\title{
Physiotherapeutic Approaches to Treat Anal Incontinence in Women after Obstetric Trauma
}

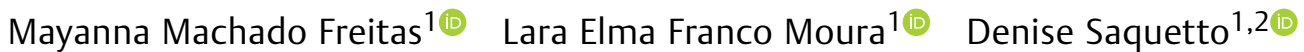 \\ lane Castro Rodrigues ${ }^{10}$ Valéria Conceição Passos de Carvalho ${ }^{1,3}$ Silvana Maria Macedo Uchôa ${ }^{1,3(1)}$
}

${ }^{1}$ Evidence-Based Physiotherapy Research Group, Universidade Católica de Pernambuco (UNICAP), Recife, Pernambuco, Brazil

${ }^{2}$ Centro Universitário Faculdade de Medicina do ABC, Santo André, São Paulo, Brazil

${ }^{3}$ Universidade Católica de Pernambuco (UNICAP), Recife,

Pernambuco, Brazil

J Coloproctol 2022;42(1):77-84.
Address for correspondence Mayanna Machado Freitas, Physiotherapist, Avenida Santa Fe, 2.843, 6D, Recoleta, CP: 1425, Buenos Aires, Argentina (e-mail: fisiomayannamachado@gmail.com).

\begin{abstract}
Introduction Anal incontinence is defined as the loss of voluntary control of fecal matter or gases with a recurrence period longer than 3 months in individuals aged $\geq$ 4 years; it has a female predominance. Among the treatment modalities is pelvic physiotherapy, the second line of treatment, which promotes the reeducation, coordination, and strengthening of the muscles of the pelvic floor to enable patients to return to their regular activities of daily living.

Objective To perform a systematic review on the physiotherapeutic treatments used in women between the ages of 18 and 65 years with a diagnosis of anal incontinence. Material and methods Clinical studies written in Portuguese, Spanish and English were searched on the the following databases: Science Direct, Medical Literature Analysis and Retrieval System Online (Medline) via PubMed, Physiotherapy Evidence Database (PEDro), Scientific Electronic Library Online (SciELO), and Scopus.

Results Of the 998 articles found, only 4 studies met the inclusion criteria of the present systematic review. The physiotherapeutic approaches to treat women with

\section{Keywords}

- fecal incontinence

- rehabilitation

- physiotherapy modalities anal incontinence are biofeedback, Kegel exercises, electrostimulation, and training of the pelvic floor muscles. The average score on the PEDro scale was of 6.25 , which indicates that the methodological quality was good.

Conclusion Although pelvic physiotherapy is effective to treat anal incontinence, it must be promoted through the performance of evidence-based scientific research.
\end{abstract}

\section{Introduction}

Fecal incontinence (FI) is defined as the loss of voluntary control of stool with a recurrence period longer than 3 months in individu- als aged $\geq 4$ years. ${ }^{1}$ When there is gas leakage, associated or not with the loss of feces, the term anal incontinence (AI) is used. ${ }^{2,3}$

It is a health condition that affects $\sim 7 \%$ of the general population, with a female predominance ${ }^{4,5}$ and a received

May 23, 2021

accepted after revision

August 6, 2021

published online

February 14, 2022
DOI https://doi.org/

$10.1055 / \mathrm{s}-0042-1742621$.

ISSN 2237-9363. (c) 2022. Sociedade Brasileira de Coloproctologia. All rights reserved.

This is an open access article published by Thieme under the terms of the Creative Commons Attribution-NonDerivative-NonCommercial-License, permitting copying and reproduction so long as the original work is given appropriate credit. Contents may not be used for commercial purposes, or adapted, remixed, transformed or built upon. (https://creativecommons.org/ licenses/by-nc-nd/4.0/)

Thieme Revinter Publicações Ltda., Rua do Matoso 170, Rio de Janeiro, RJ, CEP 20270-135, Brazil 
multifactorial etiology, including traumatic, neurological, congenital and iatrogenic factors. Among the causes mentioned, the most common are obstetric trauma and unsuccessful anorectal surgery. ${ }^{6}$

There are 3 subtypes of FI: passive incontinence, in which there is an unnoticed (involuntary) loss of feces or gas; urge incontinence, characterized by the unsuccessful attempt to retain stool, which indicates an injury to the external sphincter; and soiling, which is defined as the involuntary loss of rectal contents after evacuation due to an injury to the internal sphincter, with soiling of the perianal area and underwear. $1,7,8$

In the affected patients, this clinical condition triggers a series of consequences such as embarrassment, social isolation, low self-esteem, and changes in lifestyle and quality of life (QOL). ${ }^{9}$ As the perception of QOL is very subjective, some scales help to measure the impact of FI on it, such as the Fecal Incontinence Quality of Life (FIQOL) index, which assesses lifestyle, coping/behavior, self-perception, and embarrassment, ${ }^{10}$ and the Manchester Health Questionnaire (MHQ), which measures eight domains: impact of the incontinence, role, physical function, social function, personal relationships, emotions, sleep and energy, and the severity of the incontinence. $^{11}$

Theere are multiple treatment modalities for AI, which can be conservative and/or surgical. Conservative therapy is usually chosen as the first-line treatment, with no initial need for invasive methods in these patients. Only when the proposed treatment is not effective patients are submitted to surgical procedures (sphincter repair, overlapping repair, muscle transposition, prosthesis implantation, sacral neuromodulation, and ostomies). ${ }^{12-14}$

Changing eating habits, controlling the diet, and drinking fluids are the first steps to help these individuals in the formation of a consistent stool, thus avoiding frequent bowel movements. In addition, constipating agents such as loperamide are also prescribed to increase the time of intestinal transit through the small intestine and colon to form more consistent stools. ${ }^{15}$

Currently, pelvic physiotherapy stands out as a possible line of treatment, since its techniques promote reeducation, coordination, and strengthening of the pelvic floor muscles (PFMs) to restore the QOL of these individuals and to enable them to return to their daily life activities (DLAs). ${ }^{1}$

Among the techniques used biofeedback is a therapeutic approach that helps to create a sensitive biological response, and, as a consequence, the patient improves their perception and voluntary contraction of the PFMs. ${ }^{16}$ Training with a rectal balloon aims to improve the thresholds for sensory perception and rectal capacity. ${ }^{17}$ Functional electrical stimulation is a type of excitomotor electrical current which aims to recruit nerve fibers to promote muscle strengthening and/or resistance, depending on the parameters used. ${ }^{18}$ Kinesiotherapy, on the other hand, helps to increase the muscle tone of both type-I and type-II fibers to recover continence, coordination, and strength. ${ }^{1}$

These approaches, isolated or combined, can be effective in the partial or total recovery of the functional diagnosis of these patients. Thus, the objective of the present article was to conduct a systematic review to learn about the physiotherapeutic treatments that have been used in women aged 18 to 65 years with a diagnosis of AI.

\section{Materials and Methods}

The present is a systematic review guided by a question based on the Patient, Intervention, Comparison, Outcome, Study Design (PICOs) stategy (-Chart 1): "What are the physiotherapeutic approaches to women aged between 18 and 65 years with a diagnosis of AI?".

The Health Sciences Descriptors (Descritores em Ciências da Saúde, DeCS, in Portuguese) and the Medical Subject Headings (MeSH) were consulted and combined as follows: Modalidades de Fisioterapia AND Incontinência Fecal; Fisioterapia AND Incontinência Fecal; Reabilitação AND Incontinência Fecal; Modalidades de Fisioterapia AND Incontinência Anal; Fisioterapia AND Incontinência Anal; Reabilitação AND Incontinência Anal; Modalidades de Fisioterapia AND Incontinencia Fecal; Fisioterapia AND Incontinencia Fecal; Rehabilitación AND Incontinencia Fecal; Modalidades de Fisioterapia AND Incontinencia Anal; Fisioterapia AND Incontinencia Anal; Rehabilitación AND Incontinencia Anal Physical Therapy Modalities AND Fecal Incontinence; Physical Therapy Specialty AND Fecal Incontinence; Rehabilitation AND Fecal Incontinence; Physical Therapy Modalities AND Anal Incontinence; Physical Therapy Speciality AND Anal Incontinence; Rehabilitation AND Anal Incontinence; Physiotherapy AND Fecal Incontinence: Physiotherapy AND Anal Incontinence Electricalstimulation AND Fecal Incontinence; Electrical stimulation AND Anal Incontinence; Neurostimulation AND Fecal Incontinence; Neurostimulation AND Anal Incontinence; Biofeedback AND Fecal Incontinence; Biofeedback AND Anal Incontinence; Pelvic Floor Muscle Training AND Fecal Incontinence; and Pelvic Floor Muscle Training AND Anal Incontinence.

The search was conducted on the the following databases: Science Direct, Medical Literature Analysis and Retrieval System Online (Medline) via PubMed, Physiotherapy Evidence Database (PEDro), Scientific Electronic Library Online (SciELO), and Scopus. The search and selection ofe articles was conducted by two independent researchers, with a third evaluator available in case of discrepancies.

Chart 1 Representation of the Patient, Intervention, Comparison, Outcome, Study Design (PICOs) search strategy

\begin{tabular}{|l|l|}
\hline PICOs & $\begin{array}{l}\text { Population: Women aged } 18 \text { to } 65 \text { years with } \\
\text { anal incontinence }\end{array}$ \\
\cline { 2 - 3 } & Intervention: Biofeedback \\
\cline { 2 - 2 } & $\begin{array}{l}\text { Comparison: Other physiiotherapeutic } \\
\text { interventions in anal incontinence }\end{array}$ \\
\cline { 2 - 2 } & $\begin{array}{l}\text { Outcome: Physiotherapeutic interventions to } \\
\text { treat adult women (aged } 18 \text { to } 65 \text { years) with } \\
\text { anal incontinence }\end{array}$ \\
\cline { 2 - 2 } & Study Design: Clinical trials \\
\hline
\end{tabular}


Table 1 Application form for the Relevance Tests I and II

\begin{tabular}{|c|c|c|}
\hline \multicolumn{3}{|l|}{ Application form for the Relevance Test I } \\
\hline Inclusion criteria & Yes & No \\
\hline \multicolumn{3}{|l|}{$\begin{array}{l}\text { Does the study address the physiotherapeutic treatments for adult women with anal } \\
\text { incontinence? }\end{array}$} \\
\hline \multicolumn{3}{|l|}{ Is the article in English, Portuguese or Spanish? } \\
\hline \multicolumn{3}{|l|}{ Exclusion criteria } \\
\hline \multicolumn{3}{|l|}{$\begin{array}{l}\text { Articles that did not focus primarily on physiotherapeutic treatment in women diagnosed with } \\
\text { anal incontinence; articles not written in Portuguese, Spanish or English; studies with } \\
\text { neurological patients and/or pregnant women; duplicates, reviews, editorials, letters, } \\
\text { comments, dissertations, or theses. }\end{array}$} \\
\hline \multicolumn{3}{|l|}{ Application form for the Relevance Test II } \\
\hline Inclusion criteria & Yes & No \\
\hline \multicolumn{3}{|l|}{$\begin{array}{l}\text { Does the study describe the physiotherapeutic treatments used in adult women with anal } \\
\text { incontinence? }\end{array}$} \\
\hline \multicolumn{3}{|l|}{ Exclusion criteria } \\
\hline $\begin{array}{l}\text { Does the article not focus on the physiotherapeutic treatment for adult women diagnosed } \\
\text { with anal incontinence? }\end{array}$ & & \\
\hline
\end{tabular}

The inclusion criteria were: clinical studies that addressed physical therapy treatments in women aged 18 to 65 years with AI. And the exclusion criteria were: articles that did not focus on physiotherapeutic treatment in female patients diagnosed with AI; articles not written in Portuguese, Spanish or English; articles with neurological patients and/or pregnant patients; and duplicates, review articles, editorials, letters, comments, dissertations or theses.

The articles were submitted to the Relevance Test I (RTI), by reading the titles and abstracts. Then, those that were selected were submitted to the Relevance Test II (RTII), in which the full texts of the articles were read (-Table 1).

Using the PEDro scale, two independent authors assessed the methodological quality, and any disparities weresolved through discussion, with the involvement of a third person if necessary. The results of this assessment are presented in -Chart 2.

\section{Results}

A total of 998 articles were identified, and 478 were discarded because they were duplicates. Of the 520 articles left, 472 were excluded for the following reasons: 20 did not meet the language requirements; 55 were not primary studies; 383 did not present outcomes related to the proposed topic; 13 evaluated patients with neurological diseases; and 1 study was excluded because it was on a physiotherapy treatment for $\mathrm{AI}$ in pregnant women (-Fig. 1)

Regarding the number of articles found by database, the Scopus and Science Direct databases obtained the highest percentages: $45.7 \%$ and $25 \%$ respectively (-Table 2 ). As for the combined descriptors, Rehabilitation AND Fecal Incontinence, Biofeedback AND Fecal Incontinence, and Electrical Stimulation AND Anal Incontinence were the most found, with percentages of $13.4 \%, 13.3 \%$ and $10.1 \%$ respectively (-Table 3).

Chart 2 Quality assessment of the included studies $(n=4)$ according to the Physiotherapy Evidence Database (PEDro) scale

\begin{tabular}{|l|l|l|l|l|l|l|l|l|l|l|l|l|}
\hline $\begin{array}{l}\text { Evaluation criteria } \\
\text { (items) }\end{array}$ & $\mathbf{1}$ & $\mathbf{2}$ & $\mathbf{3}$ & $\mathbf{4}$ & $\mathbf{5}$ & $\mathbf{6}$ & $\mathbf{7}$ & $\mathbf{8}$ & $\mathbf{9}$ & $\mathbf{1 0}$ & $\mathbf{1 1}$ & Total \\
\hline Author (year) & & & & & & & & & & & & \\
\hline Fynes et al. $^{30}(1999)$ & 1 & 1 & 1 & 1 & 0 & 1 & 0 & 1 & 0 & 1 & 1 & 7 \\
\hline Mahony et al. $^{29}(2004)$ & 1 & 1 & 1 & 1 & 0 & 0 & 0 & 1 & 0 & 1 & 1 & 6 \\
\hline Naimy et al. $^{28}(2007)$ & 1 & 1 & 1 & 1 & 0 & 0 & 0 & 1 & 0 & 1 & 1 & 6 \\
\hline Johannessen et al. $^{36}(2016)$ & 1 & 1 & 1 & 1 & 0 & 0 & 0 & 1 & 0 & 1 & 1 & 6 \\
\hline
\end{tabular}

Notes: Score of 0 : indicates that the evaluation criteria do not meet the requirements.

Score of 1: indicates that the evaluation criteria meet the requirements.

1) Eligibility criteria and origin criteria; 2) random distribution; 3) hidden distribution; 4) comparisons to the starting point; 5) blinding of individuals; 6) blinding of therapists; 7) blinding of evaluators; 8) ratings $>85 \%$; 9) intention-to-treat analysis; 10) intergroup comparison; 11) measures of precision and variability. 


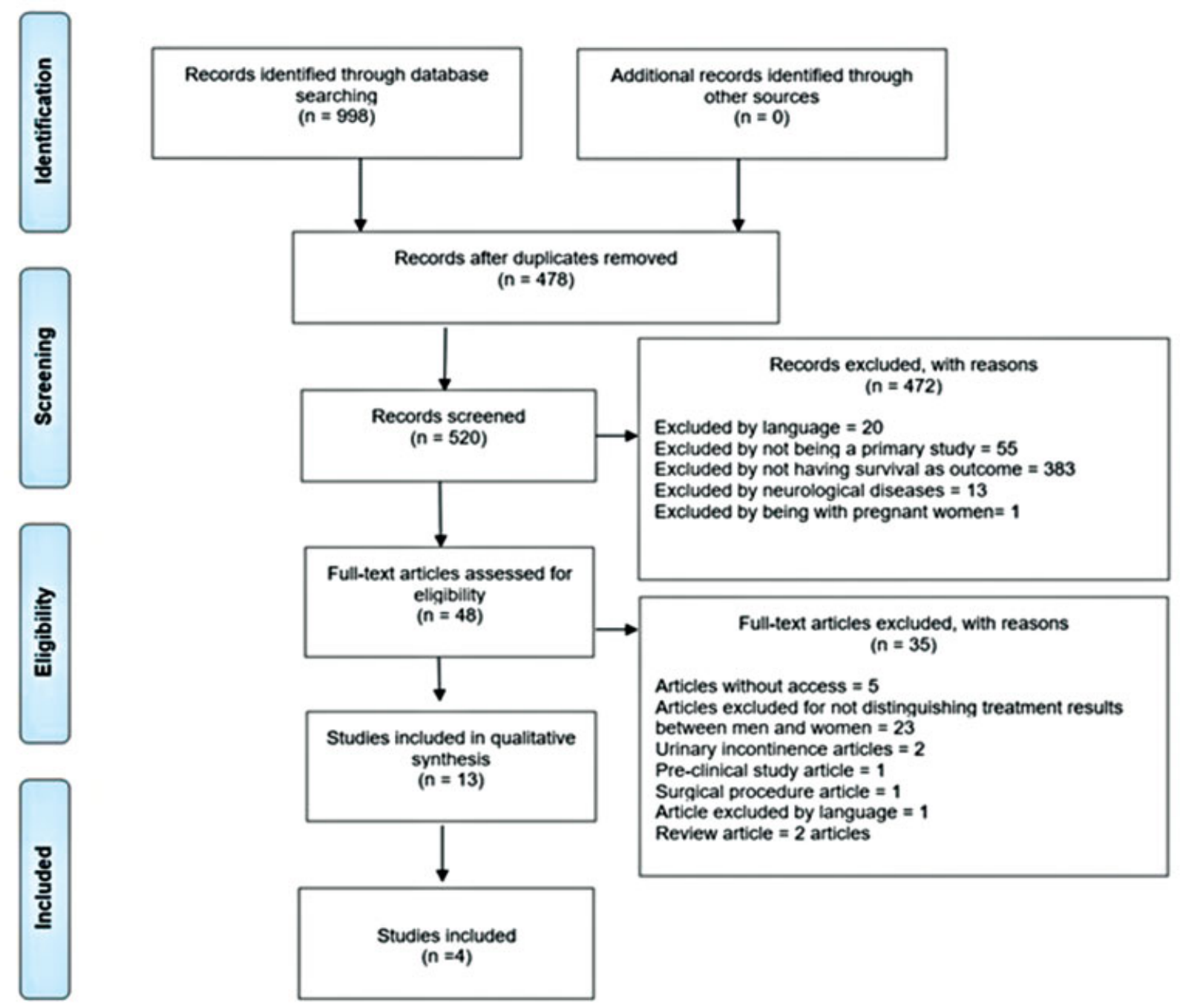

Fig. 1 Flowchart as per the Preferred Reporting Items for Systematic Reviews and Meta-Analyses (PRISMA) statement summarizing the selection of articles.

Table 2 Percentage of scientific articles found in each database

\begin{tabular}{|l|l|l|l|l|l|l|l|l|l|}
\hline \multicolumn{2}{|l|}{ SCIENCE DIRECT } & \multicolumn{2}{l|}{ PUBMED } & \multicolumn{2}{l|}{ PEDRO } & \multicolumn{2}{l|}{ SCIELO } & \multicolumn{2}{l|}{ SCOPUS } \\
\hline $\mathrm{N}$ & $\%$ & $\mathrm{~N}$ & $\%$ & $\mathrm{~N}$ & $\%$ & $\mathrm{~N}$ & $\%$ & $\mathrm{~N}$ & $\%$ \\
\hline 252 & 25 & 148 & 14.8 & 83 & 8.3 & 58 & 5.8 & 457 & 45.7 \\
\hline
\end{tabular}

Of the 998 articles found, only $4^{28-30,36}$ studies met the inclusion criteria, and - Table 4 presents their results.

The average score of 6.25 on the PEDro scale shows that, in general, the included studies are of methodological good quality. All of them used methods of random distribution (100\%); the groups were similar with regard to the most important prognostic indicators (100\%); measurements of at least one key result were obtained in more than $85 \%$ of the individuals initially distributed among the groups (100\%); and intergroup comparisons (100\%) were performed and presented the average and variability of the data regarding the results (100\%). In all studies the allocation of individuals was secret; only in 1 survey (25\%) there was blinding of the therapists, and in none of them there was blinding of individuals, blinding of the evaluators, and an analysis by intention to treat ( $\mathbf{- C h a r t} 2$ ).

\section{Discussion}

Fecal incontinence is a condition that significantly affects QOL, with high social and psychological impacts. ${ }^{19}$ According to Freeman and Menees (2016), ${ }^{20}$ the prevalence in women ranges from $2 \%$ to $25 \%$, depending on age and socioeconomic status. This data often underestimate the true prevalence, as many women avoid commenting on symptoms due to embarrassment, some doctors fail to ask about this topic during 
Table 3 Percentage of articles found according to the combined descriptors searched

\begin{tabular}{|c|c|c|}
\hline \multirow[t]{2}{*}{ COMBINED DESCRIPTORS } & \multicolumn{2}{|c|}{$\begin{array}{l}\text { ARTICLES } \\
\text { FOUND }\end{array}$} \\
\hline & $\mathrm{N}$ & $\%$ \\
\hline $\begin{array}{l}\text { Modalidades de Fisioterapia AND } \\
\text { Incontinência Fecal }\end{array}$ & 2 & 0.002 \\
\hline Fisioterapia AND Incontinência Fecal & 6 & 0.006 \\
\hline Reabilitação AND Incontinência Fecal & 6 & 0.006 \\
\hline $\begin{array}{l}\text { Modalidades de Fisioterapia AND } \\
\text { Incontinência Anal }\end{array}$ & 1 & 0.001 \\
\hline Fisioterapia AND Incontinência Anal & 4 & 0.004 \\
\hline Reabilitação AND Incontinência Anal & 1 & 0.001 \\
\hline $\begin{array}{l}\text { Modalidades de Fisioterapia AND } \\
\text { Incontinencia Fecal }\end{array}$ & 2 & 0.002 \\
\hline Fisioterapia AND Incontinencia Fecal & 6 & 0.006 \\
\hline Rehabilitación AND Incontinencia Fecal & 14 & 0.014 \\
\hline $\begin{array}{l}\text { Modalidades de Fisioterapia AND } \\
\text { Incontinencia Anal }\end{array}$ & 1 & 0.001 \\
\hline Fisioterapia AND Incontinencia Anal & 5 & 0.005 \\
\hline Rehabilitación AND Incontinencia Anal & 8 & 0.008 \\
\hline $\begin{array}{l}\text { Physical Therapy Modalities AND Fecal } \\
\text { Incontinence }\end{array}$ & 57 & 0.057 \\
\hline $\begin{array}{l}\text { Physical Therapy Specialty AND Fecal } \\
\text { Incontinence }\end{array}$ & 1 & 0.001 \\
\hline Rehabilitation AND Fecal Incontinence & 134 & 0.134 \\
\hline $\begin{array}{l}\text { Physical Therapy Modalities AND Anal } \\
\text { Incontinence }\end{array}$ & 48 & 0.048 \\
\hline $\begin{array}{l}\text { Physical Therapy Specialty AND Anal } \\
\text { Incontinence }\end{array}$ & 1 & 0.001 \\
\hline Rehabilitation AND Anal Incontinence & 72 & 0.072 \\
\hline Physiotherapy AND Fecal Incontinence & 47 & 0.047 \\
\hline Physiotherapy AND Anal Incontinence & 40 & 0.040 \\
\hline $\begin{array}{l}\text { Electrical Stimulation AND Fecal } \\
\text { Incontinence }\end{array}$ & 101 & 0.101 \\
\hline $\begin{array}{l}\text { Electrical Stimulation AND Anal } \\
\text { Incontinence }\end{array}$ & 78 & 0.078 \\
\hline Neurostimulation AND Fecal Incontinence & 33 & 0.033 \\
\hline Neurostimulation AND Anal Incontinence & 6 & 0.006 \\
\hline Biofeedback AND Fecal Incontinence & 133 & 0.133 \\
\hline Biofeedback AND Anal Incontinence & 94 & 0.094 \\
\hline $\begin{array}{l}\text { Pelvic Floor Muscle Training AND Fecal } \\
\text { Incontinence }\end{array}$ & 52 & 0.052 \\
\hline $\begin{array}{l}\text { Pelvic Floor Muscle Training AND Anal } \\
\text { Incontinence }\end{array}$ & 45 & 0.045 \\
\hline TOTAL & 998 & 100 \\
\hline
\end{tabular}

consultations, and women often avoid seeking medical attention.

The present review included 4 studies $^{28-30,36}$ regarding the effectiveness of physiotherapy treatments on the symp- toms of $\mathrm{AI}$ in adult women (aged between 18 and 65 years) after obstetric trauma, with a total population of 242 patients. The literature provides little guidance for physiotherapists and patients on rehabilitation for AI, and few studies have examined the same treatment-result combination within similar timeframes, making it impossible to perform a meta-analysis.

Regarding the initial number of articles found, most did not present titles related to the proposed topic. This is due to the lack of practice in searching for suitable descriptors using the keywords query registered in the DeCS and MeSH. ${ }^{21}$

Andalia et al. $(2010)^{22}$ performed a review on the Scopus database and showed that it contains the highest number of citations and high-quality studies related mainly to the clinical sciences. These findings corroborate those of the present study, since the Scopus yielded the highest percentage of scientific articles found (45.7\%).

Of the four articles ${ }^{28-30,36}$ included in the present review, three performed biofeedback training using different modalities (sensory biofeedback, audiovisual biofeedback, and intraanal electromyographic biofeedback). Biofeedback is a treatment to monitor physiological activities based on visual or auditory signals. ${ }^{23}$ According to Damin et al. (2017), ${ }^{24}$ it is recommended as the first-line treatment for patients with AI. It acts to improve the contraction of the external anal sphincter and the PFMs, increasing the perception and response capacity to rectal distension. According to Norton and Cody (2012) $)^{25}$ and Van Koughnett and Wexner (2013), ${ }^{26}$ biofeedback has a variable efficiency, ranging from $0 \%$ to $80 \%$, which justifies the choice of this treatment by most authors of this study.

Although there are two different devices to perform biofeedback, the objectives of both include sensory training and compliance, strength training, coordination, and resistance of the pelvic floor and sphincters. ${ }^{20}$ One is the manometer, in which it is possible to record the contraction of the external anal sphincter with pressure sensors applied to the anal canal; and the electromyographic device, which uses sensors near the anal region to detect the electromyographic activity of the pelvic floor. ${ }^{27}$

Most of the articles included in the present review used electromyographic biofeedback. Heymen et al. (2001), ${ }^{27}$ in a comparative study on the effectiveness of types of biofeedback, found an improvement in $74 \%$ of the patients undergoing treatment with electromyographic biofeedback, and $64 \%$ among those who used the manometer, contrary to the findings of Naimy et al. (2007), ${ }^{28}$ in who only observed a subjective improvement in the control of incontinence, without significant results. The multicenter study performed by Van Koughnett and Wexner $(2013)^{26}$ showed better results from biofeedback when associated with electromyography and electrostimulation for a period longer than 3 months, which is in agreement with the studies by Mahony et al. (2004) ${ }^{29}$ and Fynes et al. (1999). ${ }^{30}$

Of the three studies involving biofeedback, those by Fynes et al. (1999) $)^{30}$ and Mahony et al. (2004) ${ }^{29}$ associated rehabilitation with perianal exercises, showing significant improvement in fecal continence scores and increased average 


\begin{tabular}{|c|c|c|c|c|}
\hline $\begin{array}{l}\frac{y}{5} \\
\frac{y}{y}\end{array}$ & 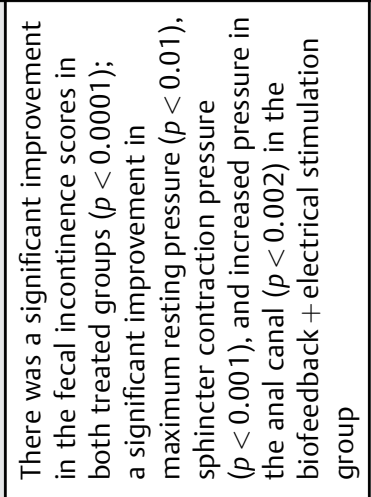 & 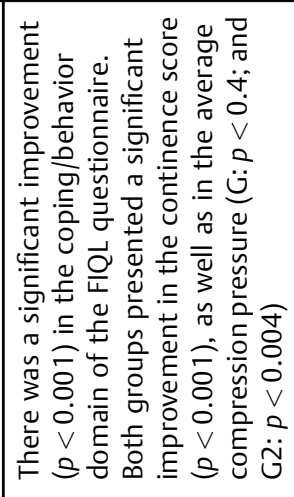 & 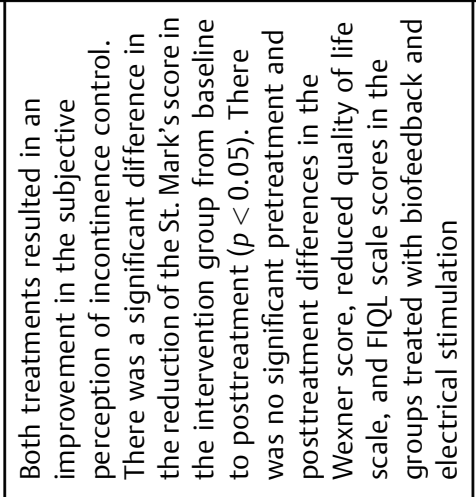 & 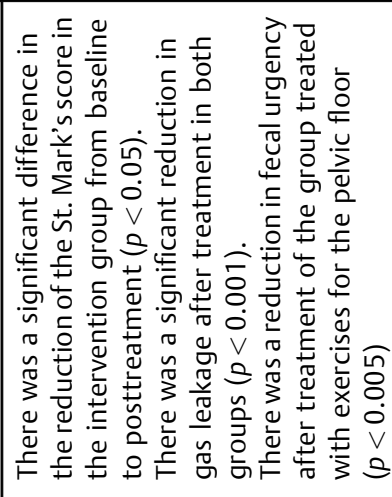 \\
\hline 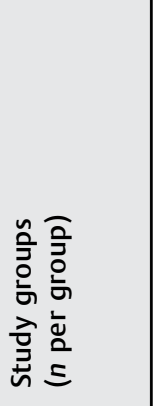 & 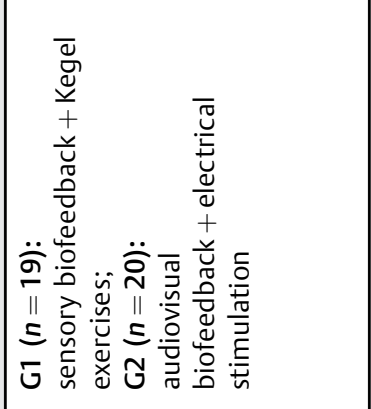 & 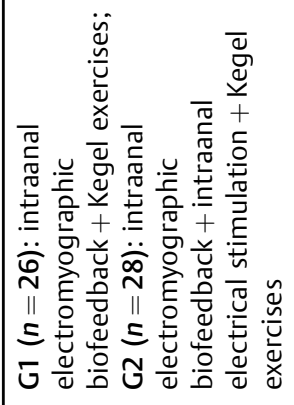 & 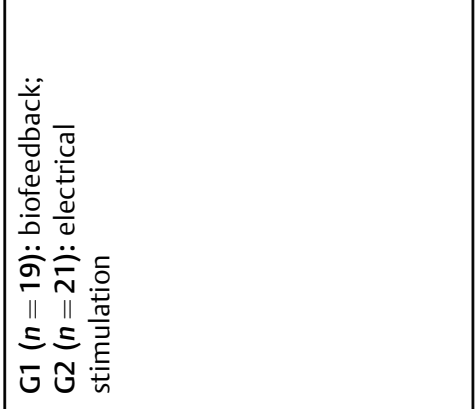 & 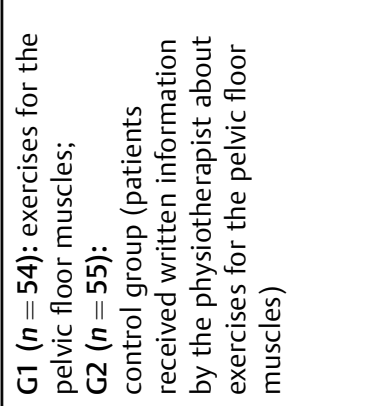 \\
\hline 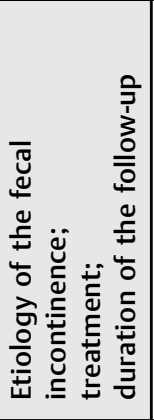 & 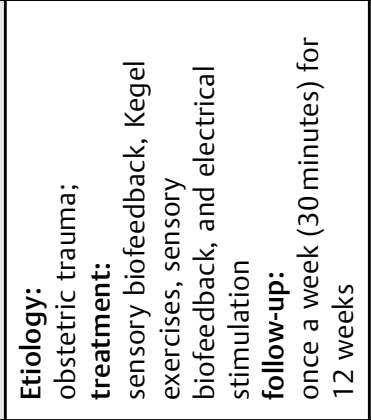 & 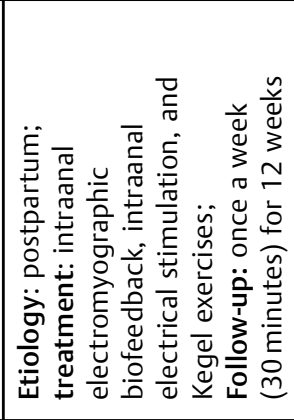 & 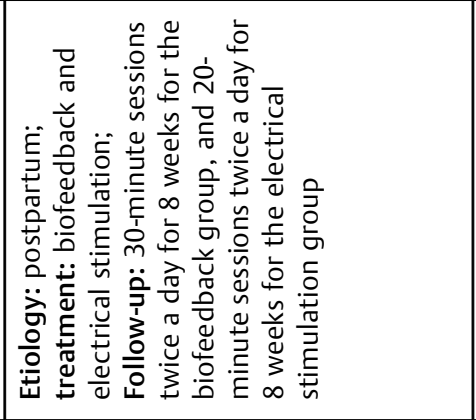 & 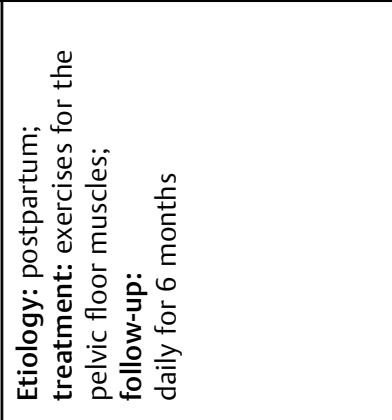 \\
\hline 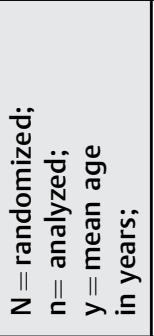 & 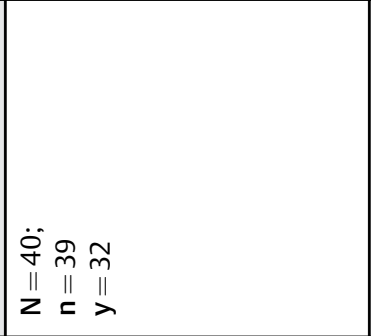 & 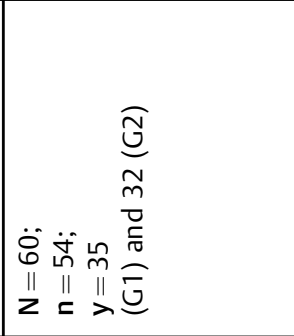 & 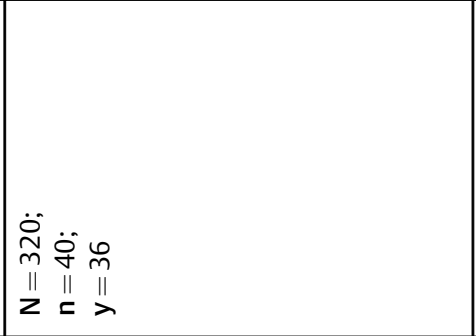 & 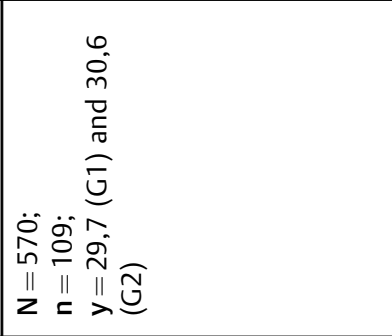 \\
\hline 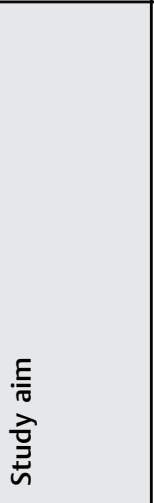 & 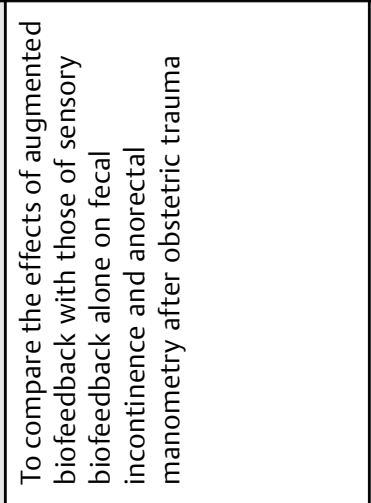 & 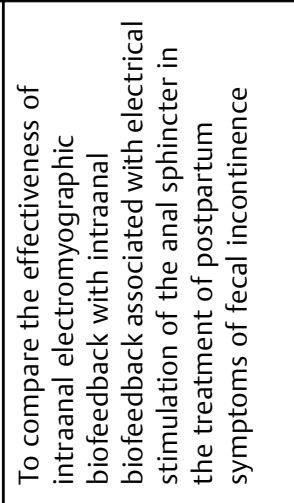 & 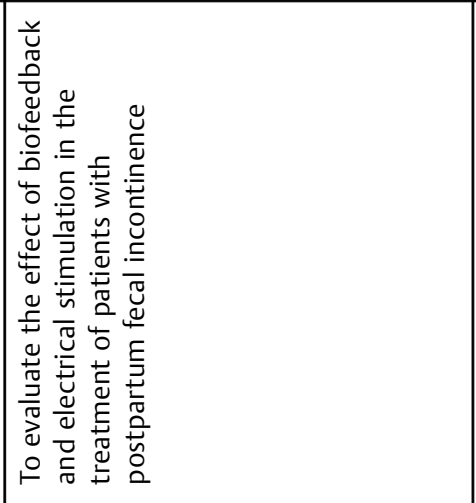 & 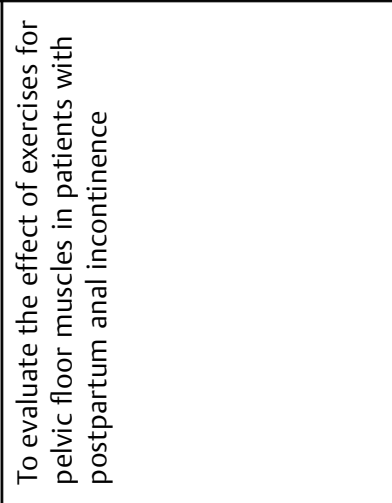 \\
\hline & 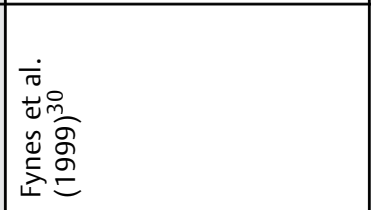 & 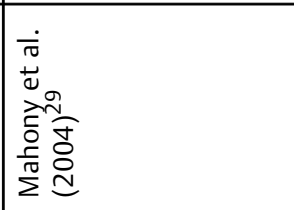 & 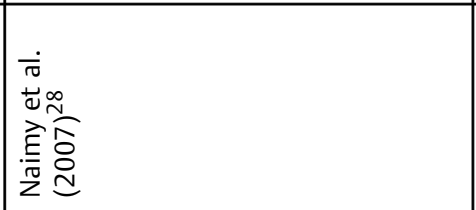 & 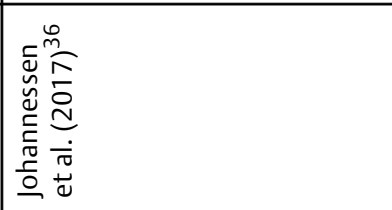 \\
\hline
\end{tabular}


sphincter pressure respectively. For Jelovsek et al. (2015), ${ }^{19}$ anal sphincter exercises with biofeedback increase the compression strength of the anal sphincter through strength training and, when combined with sensory training, may increase sensory thresholds in patients with urge incontinence (hypersensitivity).

Electrical stimulation is another therapeutic approach for the treatment of AI, which aims to provide sensorimotor stimuli for the PFMs. The application of excitomotor currents improves muscle tone and motor awareness, enabling an increase in the contraction capacity of the anal canal. ${ }^{31}$ This modality was applied intracavitaryly by Naimy et al. $(2007)^{28}$ in isolation, and by Fynes et al. (1999) ${ }^{30}$ and Mahony et al. $(2004)^{29}$ combined with audiovisual and electromyographic biofeedback respectively.

Regarding the choice of intracavitary electrical stimulation, it is noted that, unlike electrostimulation of the sacrum nerve and percutaneous tibial nerve, the sphincter is directly stimulated, improving the stability of the pelvic floor, which facilitates and can promote a better voluntary muscle contraction, avoiding the use of accessory muscles. ${ }^{32}$

There is little scientific evidence to prove the therapeutic potential of electrical stimulation in AI, which makes it difficult to apply it in isolation, as was the case of the study by Naimy et al. (2007), ${ }^{28}$ in which there was no significant improvement after the isolated application in the group treated by endo-anal electrical stimulation. However, Mahony et al. (2004) $)^{29}$ and Naimy et al. (2007) ${ }^{28}$ showed significant improvement associating biofeedback with electrostimulation, corroborating the review by Hosker et al. (2000), ${ }^{33}$ who reported benefits of both treatments together in the short term in cases of AI after obstetric trauma.

Rehabilitation of the PFMs is a term that incorporates different approaches, including PFM training performed under the guidance of a pelvic physiotherapist. Physiotherapy aims to improve strength, tone, resistance, and muscle coordination, in addition to promoting perineal awareness and improving sensitivity. ${ }^{34}$ García López $(2002)^{35}$ reported that perianal exercises improve the coordination and strength of the pelvic floor, as well as the functional tone in the voluntary contraction of the external anal sphincter and muscle mass of the pelvic floor, without interfering with the internal anal sphincter.

Exercises for the PFMs are effective in preventing and treating $\mathrm{AI}$ in pregnant women and in those in the postpartum period, as evidenced by Johannessen et al. (2017), ${ }^{36}$ with a significant reduction in the incontinence score, gas leakage and fecal urgency. In addition, one of the fundamental factors for the success of rehabilitation is the sensorymotor awareness of the pelvic region and a good patient-therapist relationship to provide information and instructions on the treatment. This could also be observed in the study by Johannessen et al. (2017), ${ }^{36}$ in which the control group, who received only written information by the physiotherapist about exercises for the PFMs, did not achieve any significant improvement.

\section{Conclusion}

In the present review, we recorded the following techniques for the treatment of AI and FI: pelvic floor exercises; muscle strength and endurance training guided by biofeedback; rectal sensitivity guided by biofeedback; and coordination and electrical stimulation training. The average score on the PEDro scale of the four articles included in the present study was of 6.25; therefore, it was not possible to assess the real cost-benefit ratio in relation to the techniques used. However, it is necessary to emphasize that the results of the application of these techniques were promising regarding the improvement of the symptomatic framework. There is an evident need for studies with better frameworks to validate the effectiveness of the techniques used in the treatment of AI and IF.

\section{Conflict of Interests}

The authors have no conflict of interests to declare.

\section{References}

1 Barroso AMF, Arruda e Sá MTM, Nunes EFC, Latorre GFS. Abordagem fisioterapêutica na incontinência fecal: revisão de literatura. Fisioterapia Ser. 2018;13(04):426-430

2 Lumi CM, Muñoz JP, La Rosa L. Neuromodulación sacra para el tratamiento de la incontinencia anal. Técnica y presentación de la primera experiencia nacional / Sacral neuromodulation for the treatment of anal incontinence. Technique and presentation of the first national experience Rev Argent Coloproctología. 2006;17 (02):104-109

3 Barbosa JMM, Dias RC, Pereira LSM. Qualidade de vida e estratégias de enfrentamento em idosos com incontinência fecal: uma revisão da literatura. Rev Bras Geriatr Gerontol 2007;10(03): 383-400. Doi: 10.1590/1809-9823.2007.100310 [Internet]

4 Nelson R, Norton N, Cautley E, Furner S. Community-based prevalence of anal incontinence. JAMA 1995;274(07):559-561

5 Lumi CM, Miravalle OR, La Rosa L, et al. Ecografía anorrectal y manometría en el estudio de pacientes con incontinencia fecal. Acta Gastroenterol Latinoam 2012;42(03):193-198

6 Hayden DM, Weiss EG. Fecal incontinence: etiology, evaluation, and treatment. Clin Colon Rectal Surg 2011;24(01):64-70. Doi: 10.1055/s-0031-1272825

7 Muñoz-Duyos A, Montero J, Navarro A, Del Río C, García-Domingo MI, Marco C. Incontinencia fecal: Neurofisiología y neuromodulación. Cir Esp 2004;76:65-70. Doi: 10.1016/S0009-739X(04) 72362-3

8 Leite J, Poças F. TRATAMENTO DA INCONTINÊNCIA FECAL. Rev Port Coloproct. 2010;7(02):68-72

9 Meyer I, Richter HE. Impact of fecal incontinence and its treatment on quality of life in women. Womens Health (Lond) $2015 ; 11$ (02):225-238. Doi: 10.2217/whe.14.66

10 Rockwood TH, Church JM, Fleshman JW, et al. Fecal Incontinence Quality of Life Scale: quality of life instrument for patients with fecal incontinence. Dis Colon Rectum 2000;43(01):9-16, discussion 16-17. Doi: 10.1007/BF02237236

11 Kwon S, Visco AG, Fitzgerald MP, Ye W, Whitehead WEPelvic Floor Disorders Network (PFDN) Validity and reliability of the Modified Manchester Health Questionnaire in assessing patients with fecal incontinence. Dis Colon Rectum 2005;48 (02):323-331, discussion 331-334. Doi: 10.1007/s10350-004$0899-\mathrm{y}$

12 Lumi CM, Muñoz JP. Tratamiento quirúrgico de la incontinencia anal. ECirugía Digestiva. 2009;III-368:1-1 
13 Vergara MT, Suárez JM, Orellana HG, et al. Incontinencia fecal del adulto. Rev Chil Cir 2011;63(03):320-326. Doi: 10.4067/S071840262011000300016 [Internet]

14 Duelund-Jakobsen J, Worsoe J, Lundby L, Christensen P, Krogh K. Management of patients with faecal incontinence. Therap Adv Gastroenterol 2016;9(01):86-97. Doi: 10.1177/1756283X15614516

15 Nakano K, Takahashi T, Tsunoda A, Shimizu Y. Effects of Dietary Guidance without Dietary Fiber Supplements on the Symptoms, Quality of Life, and Dietary Intake in Patients with Fecal Incontinence. J Anus Rectum Colon 2020;4(03):128-136. Doi: 10.23922/ jarc.2020-008

16 Guerra-Mora JR, Buenrostro-Acebes JM, Erciga-Vergara N, et al. Efectividad del biofeedback en pacientes con incontinencia fecal. Rev Med Inst Mex Seguro Soc 2015;53(04):472-475

17 Murad-Regadas SM, Regadas FSP, Regadas Filho FSP, Mendonça Filho JJ, Andrade Filho RS, Vilarinho ADS. Predictors of unsuccessful of treatment for fecal incontinence biofeedback for fecal incontinence in female. Arq Gastroenterol 2019;56(01):61-65 cited2021May09. Doi: 10.1590/s0004-2803.201900000-17 [Internet]

18 Yik YI, Stathopoulos L, Hutson JM, Southwell BR. Home Transcutaneous Electrical Stimulation Therapy to Treat Children With Anorectal Retention: A Pilot Study. Neuromodulation 2016;19 (05):515-521. Doi: 10.1111/ner.12451

19 Jelovsek JE, Markland AD, Whitehead WE, et al; National Institute of Child Health and Human Development Pelvic Floor Disorders Network. Controlling faecal incontinence in women by performing anal exercises with biofeedback or loperamide: a randomised clinical trial. Lancet Gastroenterol Hepatol 2019;4(09):698-710. Doi: 10.1016/S2468-1253(19)30193-1

20 Freeman A, Menees S. Fecal Incontinence and Pelvic Floor Dysfunction in Women: A Review. Gastroenterol Clin North Am 2016; 45(02):217-237. Doi: 10.1016/j.gtc.2016.02.002

21 Brandau R, Monteiro R, Braile DM. Importância do uso correto dos descritores nos artigos científicos. Rev Bras Cir Cardiovasc 2005;20 (01):VII-IX. Doi: 10.1590/S0102-76382005000100004 [Internet]

22 Andalia RC, Rodríguez-Labrada R, Castells MM. Scopus: la mayor base de datos de literatura científica arbitrada al alcance de los países subdesarrollados. Acimed 2010;21:270-282

23 Bertotto A, Schvartzman R, Uchôa S, Wender MCO. Effect of electromyographic biofeedback as an add-on to pelvic floor muscle exercises on neuromuscular outcomes and quality of life in postmenopausal women with stress urinary incontinence: A randomized controlled trial. Neurourol Urodyn 2017;36(08): 2142-2147. Doi: 10.1002/nau.23258

24 Damin DC, Hommerding F, Schirmer D, et al. Patient-Controlled Biofeedback Device for the Treatment of Fecal Incontinence: A
Pilot Study. Appl Psychophysiol Biofeedback 2017;42(02): 133-137. Doi: 10.1007/s10484-017-9352-6

25 Norton C, Cody JD. Biofeedback and/or sphincter exercises for the treatment of faecal incontinence in adults. Cochrane Database Syst Rev 2012;7(7, CD002111):CD002111. Doi: 10.1002/14651858. CD002111.pub3

26 Van Koughnett JA, Wexner SD. Current management of fecal incontinence: choosing amongst treatment options to optimize outcomes. World J Gastroenterol 2013;19(48):9216-9230. Doi: 10.3748/wjg.v19.i48.9216

27 Heymen S, Jones KR, Ringel Y, Scarlett Y, Whitehead WE, Whitehead WE. Biofeedback treatment of fecal incontinence: a critical review. Dis Colon Rectum 2001;44(05):728-736. Doi: 10.1007/ BF02234575

28 Naimy N, Lindam AT, Bakka A, et al. Biofeedback vs. electrostimulation in the treatment of postdelivery anal incontinence: a randomized, clinical trial. Dis Colon Rectum 2007;50(12):2040-2046. Doi: 10.1007/s10350-007-9075-5

29 Mahony RT, Malone PA, Nalty J, Behan M, O'connell PR, O'herlihy C. Randomized clinical trial of intra-anal electromyographic biofeedback physiotherapy with intra-anal electromyographic biofeedback augmented with electrical stimulation of the anal sphincter in the early treatment of postpartum fecal incontinence. Am J Obstet Gynecol 2004;191(03):885-890. Doi: 10.1016/j.ajog.2004.07.006

30 Fynes MM, Marshall K, Cassidy M, et al. A prospective, randomized study comparing the effect of augmented biofeedback with sensory biofeedback alone on fecal incontinence after obstetric trauma. Dis Colon Rectum 1999;42(06):753-758, discussion 758-761. Doi: 10.1007/BF02236930

31 Longo GJ, Fuirini N. Correntes de alta freqüência: ondas curtas. São Paulo: KLD biossistemas equipamentos eletrônicos. LTDA, 2000

32 Jost WH, Loch EG, Müller-Lobeck H. [Electrophysiologic studies of fecal incontinence in the woman]. Zentralbl Gynäkol 1998;120 (04):153-159

33 Hosker G, Norton C, Brazzelli M. Electrical stimulation for faecal incontinence in adults. Cochrane Database Syst Rev 2000;1(2, CD001310):CD001310. Doi: 10.1002/14651858.CD001310

34 Lunniss PJ, Gladman MA, Hetzer FH, Williams NS, Scott SM. Risk factors in acquired faecal incontinence. J R Soc Med 2004;97(03): 111-116

35 García López AJ. Incontinencia anal. Iatreia [Internet] 2002;15 (03):190-199

36 Johannessen HH, Wibe A, Stordahl A, Sandvik L, Mørkved S. Do pelvic floor muscle exercises reduce postpartum anal incontinence? A randomised controlled trial. BJOG 2017;124(04): 686-694. Doi: 10.1111/1471-0528.14145 